\title{
SPECIAL FEATURE: PREFACE \\ Population and Economic Development in East Asia \\ Preface to the special feature on population and economic development in East Asia
}

\section{Tomoko Kinugasa $^{1}$}

Received: 25 December 2019 / Accepted: 29 December 2019 / Published online: 6 February 2020 (c) Japan Economic Policy Association (JEPA) 2020

The 18th International Conference of the Japan Economic Policy Association (JEPA18) was held on 16-17th, November, 2019 at Chuo University, Tokyo, Japan. Among sessions presented in the conference, a plenary session invited several distinguished scholars on the topic of population and economic growth in East Asian countries, which leads to the present special feature. Here presented are three papers that are written by the invited speakers and the session chair.

Asia is now becoming the primary growth engine and the new center of the world economy. In the 2020s, Asian economies will grow larger than the rest of the world combined in terms of middle-class population and economic output, which stimulates extensive discussions among economists and political scientists. In this feature, the research subjects are Japan and China. These two countries are the leading developed and developing economies in East Asia. Japan has completed demographic transition in the latter half of twentieth century. During the period, Japan experienced remarkable economic development. Japan became one of the developed countries and more and more women participated in labor force. Nowadays, fertility has been very low, population has been declining, and population aging has become a serious problem in Japan.

The first paper is titled "Does a Relationship between Fertility and Labor Participation of Women Really Exist?-Perspectives from Time Series Analysis" and written by Hisakazu Kato. So far, the existing research has discovered neither concrete evidence nor satisfactory explanation for the puzzling relationship between fertility and female labor supply. In contrast to previous cross-country analyses, the present paper employs time series analysis to estimate the empirical relationship between fertility and female labor force participation in Japan. The author raises the possibility of spurious correlation and finds that the positive correlation can be primarily attributed to a third variable - the female wage, consistent with theoretical derivations and economic intuitions. The author also presents empirical support for the

Tomoko Kinugasa

kinugasa@econ.kobe-u.ac.jp

1 Graduate School of Economics, Kobe University, 2-1, Rokkodai, Nada-ku, Kobe 657-8501, Japan 
effectiveness of government policies in improving the total fertility rate. In concluding remarks, the author points out unresolved problems in the research and provides promising directions for future research.

On the other hand, as the largest economy in Asia, China has achieved unprecedented economic success in the past decades due to the first demographic dividend and its unique growth models. China's economic development, however, is now facing tremendous challenges under the diminishing demographic dividend and the unsustainable growth pattern, which has raised numerous questions and received widespread research attention. Against this backdrop, the transitions in demographic structure and growth strategy will create both challenges and opportunities for the future development of China.

The second and third paper is about population and economy in China. The title of the second paper is, "Demographic Transition and Economic Miracles in China: An Analysis based on Demographic Perspective" written by Xin Yuan and Yuan Gao. This paper focuses their attention on the dramatic change in age structure caused by demographic transition. The authors insist that demographic window, that is plenty of labor force, will become a key for economic development. The demographic window cannot become a demographic dividend or facilitate economic growth without compatible domestic economic and social development policies and the globalized international economic environment for peaceful development. They stress that China has successfully taken advantage of favorable demographic situation.

The title of the third paper is: "Challenges for China's economic development: the saving glut and policy implication ", written by Kevin Luo and Tomoko Kinugasa. In this paper, the authors discover that China has been in a severe state of capital overaccumulation. In the empirical analysis, the authors find that the commonlyregarded favorable factors (e.g., the education reform) have actually aggravated the overaccumulation problem, and the generally-considered unfavorable factors (e.g., public investment expansion) have essentially attenuated the overaccumulation in China. This evidence implies that China has achieved substantial economic success through the capital-extensive growth pattern, but now it is imperative for Chinese economy to rebalance its growth strategy and create a more consumption-oriented environment.

The two studies employ different approaches to deconstruct China's long-term economic success from demographic and accumulation perspectives. Both studies discover that the "opening up strategy," the education reform, the state-owned enterprise reform, the rapid income growth, and the financial liberation have significantly contributed to China's economic growth via either demographic or accumulation mechanisms. They emphasize the important role of structural reforms in coping with the diminishing capital return in China (the overaccumulation problem). 